\title{
FOOD INDUSTRY WORKERS' ATTITUDES ON THE IMPORTANCE OF FACTORS AFFECTING FOODSTUFF QUALITY MANAGAMENT
}

\author{
UDC: $005.6: 664$ \\ Original Scientific Paper \\ Zorana ANTIĆ ${ }^{1}$, Srđan BOGETIĆ ${ }^{2}$ \\ ${ }^{1}$ Belgrade Business School, 11000 Belgrade, Kraljice Marije 73, Republic of Serbia \\ ${ }^{2}$ Belgrade Business School, 11000 Belgrade, Kraljice Marije 73, Republic of Serbia \\ E-mail: srdjan.bogetic@bbs.edu.rs
}

Paper received: 19.04.2015.; Paper accepted: 21.05.2015.

\begin{abstract}
The food industry is faced with several challenges at the same time: to supply safe and affordable foodstuff in sufficient quantity; to provide products in conditions where demand surpasses the human population growth; to operate in circumstances of ever-increasing competition; to protect the environment and respond to the population's public health concerns. An organization's success depends on the knowledge, skills, creativity and motivation of the company's workers and partners. Focus on its employees enables a company's development and improvement, whereas business ethics ensures public health and safety protection, environmental protection and life quality improvement. The company management's responsibility lies foremost in education, worker training and development, thus enabling a direct and indirect influence on the foodstuff quality and satisfying consumer requests in terms of foodstuff quality characteristics.
\end{abstract}

Keywords: foodstuff, quality, food industry, workers, improvement.

\section{INTRODUCTION}

Globalization has a significant influence on food and the food industry system worldwide by affecting the availability and access to foodstuff through changes in food production, procurement and distribution and thus bringing gradual shift in food culture with consequent changes in habits when it comes to nutrition and consumption that vary by socioeconomic status (Kennedy et al., 2004).

When it comes to foodstuff production consumers emphasize three important requirements that the product should fulfill, namely: to be healthy, convenient for consumption and tasty. Food quality changes during the food supply chain, since it depends on environmental factors, technological process, development, control, improvement and quality assurance (Luning et al., 2002).

There are two models by which the characteristics of food quality are classified. Interior features are physically indistinguishable from the product and are noticeable (the characteristics of texture and taste) or attached (safety, health) and are also a result of physical, chemical and other properties of foods $(\mathrm{pH}, \quad$ composition, microbiological contamination).

External characteristics do not necessarily have to be related to the properties of the product, but may affect the consumer's perception of quality. These characteristics are associated with the production and marketing aspects of the product, but also affect the acceptance of products (animal welfare, sustainability of production, brand name).

The legislation is the most important as it affects the quality and / or the characteristics of the product (food declaration demands, organic production) by its requirements and restrictions related to the characteristics of the product (composition), technological conditions (e.g. temperature, time) and the control system (hygiene rules, procedures, quality system). 


\section{FOODSTUFF QUALITY}

The control of food products quality is necessary to understand and analyze the characteristics of quality, because depending on the position in the food supply chain, participants may have different concepts of quality and different interpretations of quality characteristics. Moreover, consumers evaluate the quality in their own way (they evaluate texture, taste, packaging), without taking into consideration the quality depending on the ingredients (such as vitamins) but rather concentrating on the safety and healthiness of the product. The above factors should be translated into product characteristics, technological conditions and requirements so that the desired level of acceptance by the consumer (buyer) could be obtained. In many countries there is a strong interaction of the consumer and producer, a system in which the strict boundaries between consumers and producers are progressively erased. Execution of a specific job is increasingly dependent on knowledge, and confidence between the parties becomes extremely important (Hruškar et al., 2010).

The demands considered as the initiators of management in the supply chain can be divided into four groups (Hruškar et al., 2010):

1. consumer demands - include the needs of production methods, food availability, food and environment quality;

2. productivity and technology - include effectiveness and influence of the processes (information technology, logistics, biotechnology, measurement and monitoring);

3. management - regulations and policies (transition to a market economy, opening towards the global market, parallel approximation and so on);

4. resources - the need for capital, raw materials and labor.

Improvement of products and production processes is significant for the quality of food products. The competition insists on the manufacturer's innovation and improvement of products with reduced production costs. Quality control is a continuous process of development of products or services that meet consumer demands. Quality control involves enforcement of the activities that ensure the achievement of the set objectives, including evaluation of the implementation policy and the quality of the set goals as well as undertaking corrective actions when goals are not met. Improvement can be achieved by focusing on the issues that are strategically relevant for the company.

Basic competencies and skills needed in the food industry are technical or technological nature and therefore expertise (competence) should be improved and the appropriate skills should be upheld to support management activities. Management improvement tools are determined by measurement and information system. Information should include a critical points of quality and food products safety that are associated with technological competence, and at the same time they must be easily accessible and applicable for statistical analysis (such as Pareto diagrams, standard deviation, etc.), in order to adopt appropriate decisions.

The second basic activity necessary for improving the quality is education. Education of staff should be directed to the relevant technological and management knowledge for the specific quality control points they are responsible for. The adoption of basic statistical techniques is necessary for organizing and data processing because they are used for analysis and argumentation. Moreover, the food industry contributes nutrition education by offering products that meet the current needs of consumers and by informing them about the ingredients and nutritional characteristics of the product. Bearing in mind the important role that the industry has to supply the population, education is seen as one of the social responsibility of the food industry. In industrialized countries, food companies are heavily involved in the education of consumers using all available communication channels such as packaging, advertising, informational pamphlets, educational materials in schools, professional associations of consumers, agencies and the like. In developing countries, nutrition education may have a beneficial effect on the rational and proper use of available stocks. Despite the communication problems, food manufacturers can also contribute to consumer education, particularly through packets, informational brochures and their distribution network. It shouldn't be forgotten that the promotion of consumer education is the responsibility of the authorities in charge of education and health.

Joint actions are required to improve the system of quality given the fact that the quality of the end of the food chain depends on the implementation of quality throughout the food chain, 


\section{CHARACTERISTICS OF EFFECTIVE ORGANIZATIONS IN FOOD INDUSTRY}

Food industry operates in entirely different conditions than it was the case a few decades ago. The new business environment is characterized by the growth in raw material costs, price pressures of traders and more rigorous regulations. The role of consumers has also changed, as they require a higher nutritional value and use of ingredients that are considered to be safer for the environment. In this context, ti is no longer sufficient for the customers that food products meet only the basic requirements. Today, companies operating within the food industry must provide strategies that will enable the creation of products that will fulfill all customers' requirements.

Consumers want a greater variety of food products, healthier and tastier products for the same or lower price. On the other hand, they also require more information about the food they consume. In response to the request of the customer, some retail chains have offered assessment of the nutritional value of the product on the shelf, and the World Health Organization and the Governments of some countries have recommend development of a rating system for the food nutrition that should be mentioned on the label. The demand for healthier and high-quality food products is not limited to consumers with the highest income. The supermarket chain Lidl, which is present throughout the European Union, has asked its suppliers to remove sweetener - synthetic betacarotene from products and to start using Stevia instead, which is a replacement based on the natural sugar (Anthony, 2012).

Influence from the suppliers of food companies is reflected in higher prices and fluctuations in the quality and chemical composition of raw materials. Food prices have an upward trend, according to numerous reports, including the report of the Food and Agriculture Organization of the United Nations in 2012 (FAO, 2012). The analysis of food prices from 1961 to 2010, have shown that for most of the period, the food prices had a downward path, while the price increase began in 2003, a sudden jump occurred from 2006 to 2008. After a brief decline in 2008, food prices began to rise sharply in mid-2010 and this tendency is still present. The report predicts re-fluctuation of food prices in the for-coming years.

On the other hand, the combination of changes in the structure of the population, rapid urbanization and global marketing of food products, have led to changes in the energy balance equation for millions of people in a very short time - period of just a few decades. This tendency has resulted in higher rates of obesity and chronic diseases, while dedicated and socially responsible efforts targeted to provide greater access to higher quality of nutrition and adequate physical activity is still lacking.

According to the World Health Organization in $2008,35 \%$ of the population (more than 1.4 billion people), with 20 years of age and older, were overweight, of which more than 200 million were men and nearly 300 million women. Data for 2011 have show that more than 40 million children under five years of age are obese. Increased body weight and obesity are on the rise in low- and middle-income countries, particularly in urban areas. More than 30 million obese children live in developing countries and 10 million in developed countries. It is anticipated that by 2015 about 2.3 billion people will be overweight and that more than 700 million will be obese (WHO, 2013).

Today, the food industry faces with the challenge of how to meet the ever-increasing range of customer requirements and environments (other companies, regulations, etc.). The requirements do not imply only quality of the products, price and availability, but also flexibility, maintenance and reliability of the company. Practice shown it is very difficult for the food producers to meet all those requirements.

Companies in the food industry can achieve competitive advantage only if they find a way to deliver food products faster and at lower costs. A successful response to dynamic business environment will inevitably include the formulation and implementation of strategies that will ensure (Infor, 2012):

- Delivery of products with higher nutritional value and fewer allergens - given the fact that consumers are increasingly focused on the quality, including calorie composition, allergens (such as, gluten), additives and preservatives. Companies need to improve their products in order to increase the nutritional value or eliminate undesirable ingredients but retain organoleptic characteristics such as taste, smell, color and structure;

- Achieving repeatability characteristics of food products - ingredients that are used as raw materials in the food industry have inconsistent quality and chemical composition due to the 
large influence of natural and climatic conditions, and food manufacturers have to adapt technological processes and manufacturing procedures in order to maintain the consistency of the final products. On the other hand, consumers and retailers have higher expectations when it comes to product quality, availability and price performance. The task of the food industry, in order to preserve the sustainable competitive advantage, is to create a technological procedures that eliminate or reduce the impact of the variability of ingredients that influence the quality of the finished product, enable the continuous availability of the products and preservation of the taste and quality of food products over a longer shelf life;

- Constantly lowering costs - companies engaged in the production of food, must focus its business activities towards greater efficiency and lower costs in conditions that require constant increase of the food availability (in terms of volumes, market coverage and diversity) and lower and lower prices of the food items;

- Lower environmental impact - organizations that operate within the food industry must devote great attention to environmental policies, considering the fact the obligation of safe food production - free of any potential physical, chemical and biological contaminants, and the need to respect the rules and standards for protection of the environment, such as reducing use of water, lower emissions, reduction of waste water discharges and good waste management.

Given that in the food industry is dominated with the policy of orientation towards product quality and production process, and that the food industry is based on the technology, the procedures are widely accepted and considered a powerful means which provide guarantees in technological processes. This approach often causes complications because it underestimates the impact of human behavior and decision-making. Relying on people is not widely accepted in the food industry because it is often considered to be soft and intangible access.

Consequently, it is not surprising that the quality assurance systems in the food industry seen as auxiliaries with predictable outcome and that these systems are respected and widely adopted.
The beginning of the system of quality assurance in the food industry goes back 1980s with the application of the principles of good manufacturing practice (GMP - Good Manufacturing Practices), which has set guidelines for ensuring a minimum of acceptable standards and conditions for the processing and storage of agricultural products and foodstuffs in order to ensure basic safety and quality. During the 1990s starts the introduction of standards for governing quality management system (ISO 9001), and since 1996, a rapid increase in the application of HACCP due to legal obligations, while the BRC quality assurance system integrated the principles of GMP, HACCP and ISO 9001. The first ISO international standard organization for food safety management, ISO 22000 , passed in 2005, emphasizes the food safety as a priority for all organizations that produce, process and deliver or handle food. The package of standards that need to be met for certification under the name Organic certification (BIO) is intended for producers of organic food and other agricultural products, and includes the cultivation, storage, processing, packaging and shipment (SIEPA, 2015). Kosher and Halal standards prescribed by producing and preparing food according to special regulations and traditions (Jewish and Muslim), while international commercial standard Global GAP covers the production of primary agricultural products.

Aside from the economic and environmental, followed, especially in nowadays, the issues of social sustainability, in the corporate social responsibility of the companies of the food industry are complex. The framework for the implementation of CSR in the food supply chain includes eight categories (Maloney and Brown, 2006): health and safety, animal welfare, biotechnology, community, environment, finances, employees and procurement. As the level of safety of food products depends the health and sometimes lives of the humans, consumers are particularly concerned and in recent years paid the great attention to issues of quality and safety of food products (Leung et al., 2015). In the context of CSR, the food sector is, therefore, faced with specific challenges. Firstly, the food sector is heavily influenced and directly dependent by the natural, human and physical resources. Secondly, since food is a basic human need, people have strong opinions when it comes to nutrition. This leads to a complex set of requirements that are placed in front of the food industry in connection with the production of raw materials (animal welfare), environment (eg. use of energy and 
water, waste) and social issues (working conditions) along the entire value chain. Quality, health and safety are also essential requirements. Thirdly, the food chain has a unique and complex structure. Since small and large companies have different approaches to CSR, this means potential conflicts relating to CSR activities in the food supply chain (Hartman, 2011).

Given that the promotion of products and production processes is of crucial importance for the quality of food and food products, and also considering the fact that competition is forcing manufacturers to innovate and improve products while reducing production costs, it can be concluded that for the achievement of effective organization in the food industry, it is necessary to follow the teachings of Juran. He based his theory on the statement that the quality is directly connected with pleasure or dissatisfaction of the product. Satisfaction refers to superior characteristics, and the dissatisfaction is the result of flaws and imperfections. Juran emphasizes the external dimension of the product, referring to satisfy the demands of the user, and an internal dimension, which refers to the process of making the correct product or service delivery. Jurans' concept of "quality trilogy" (Filipović and Đurić, 2009) is based on three processes important for quality: quality planning, quality management and quality improvement. Quality Planning is a continuous process of development of products or services that meet consumer demands. Quality management involves performing activities that ensure the achievement of these objectives, and evaluate the implementation of the quality policy and quality objectives set, as well as taking a certain action when goals are not met. The third phase of the Juran trilogy includes quality improvement that results in increased customer satisfaction (consumer), to achieve higher levels of quality, reduce costs, increase productivity and accelerate the process.

\section{THE IMPORTANCE OF HUMAN RESOURCES IN ACHIEVING QUALITY OF FOOD PRODUCTS}

Quality has become a key requirement for obtaining a competitive advantage, and it turned out that the inclusion of human resources management in the achievement, maintenance and improvement of quality, leads to its long-term success. Research conducted in 1993 by the Institute of Personnel Management (Institute of Personnel Management - IPM), showed that HR professionals play a significant role in the successful implementation and maintenance of quality program and that their participation is not a matter of choice, but a necessary condition, if the goal is an effective quality management (Powell, 1995)

Quality management can result in a change of a way for the conduction of the process of human resources management, as well as the role of human resources management in the organization. As a result of the inclusion of the changes brought by the implementation of quality management, human resources management should gain a strategic role, which is especially justified by the fact that the implementation of quality and adoption of the culture of quality is impossible without the guidance provided by the human resource management. Thus, human resources management and quality management have reciprocal relationship that can be represented responsive reaction: quality management causes changes in the processes of human resource management, and the success and effectiveness of the quality management affects commitment of human resources management.

The role of human resource management is also important in troubleshooting and strategic decision making. Companies that have a strategic approach to human resources management are more effectively and efficiently accessing the preparation of the program quality phase. Key decisions are made in accordance with the objectives of quality and with the full involvement of the Department of Human Resource Management, which ensures long-term success. On the other hand, companies that opt for the administrative access to human resources and do not have a department for human resources management, conduct implementation of quality programs without their involvement. Such companies cannot expect success because they lack knowledge and skills, as well as the motives for the implement of the necessary changes.

Quality management leads to changes in the role of human resources management in organizations of the food industry. Due to the rapid pace of changes in technology, international trade, market prices, competitive products, customer demands and expectations, many companies are forced to change their way of doing business. Sometimes the changes are reflect in the reduction of the number of employees and the adoption of flexible personnel practices (eg, outsourcing, 
subcontracting and temporary employees) or otherwise, which involves adoption of a system of the work with high performance (eg. autonomous working teams, flexible and flat production and just- in-time production).

From the aspect of human resources, working conditions in the food and beverage industry are heavy. The work can often be repetitive and physically demanding, with long periods of standing, causing musculo-skeletal disorders (Ergonomic Guidelines, 2007). The work in thos industries can also be dangerous, with the higher rate of injuries than the average - burns from stoves, falls, cuts from a knife or coarse blades are common and repetitive, which is a big problem. According to the US Bureau of Labor Statistics (BLS, 2015), in 2008, a there was a total of 12,200 registered diseases and injuries in the food sector, and the incidence rate for this industry (81 illness on 10,000 workers) was about four times higher than in other industries (19.7 illnesses per 10,000 workers). In addition to dominating musculoskeletal disorders on the list of the most common are the skin diseases, respiratory disease, poisoning, hearing loss and other ailments. With employees in food production there is higher degree of probability for fatal injuries and nonfatal injuries and illnesses than with those who work in other industries. In addition, compared with other industrial workers, employed in food production, due to a greater extent of injuries are more often moved to other jobs or sent on leave for medical treatment (BLS, 2008). Also, the working environment is often noisy and limits interaction between employees.

Despite all the challenges facing the food industry, there are ways for successfully reducement of disorders and injuries of employees, particularly in the manufacturing process. They rely on a combination of innovative approaches include redesigning work tasks and equipment; computer controlled equipment and application of technical achievements; rotate employees between heavier and lighter tasks; enabling shorter, more frequent breaks for rest and development of training programs for safe work practices.

Human resource managers in companies of the food industry are responsible for the development of business policy which implies the implementation of regulations and guidelines established by external regulatory bodies, such as. The World Health Organization and the Food and Drug Administration, as well as international standards governing the management system of the organization when it comes to quality, the environment, the production of safe food and health and safety at work. Human resources manager can this policy and requires that you include in the employment policy of the company, to ensure that workers are familiar with the requirements. The task manager for human resources and also ensuring compliance with this policy, providing information and support to the relevant managers for execution.

Performance management employees in the food industry is an important condition for the achievement of product quality. Human resource managers are also responsible for managing relationships between employees, or between employees and management. Assessment of the performance of employees, as a result of the evaluation, which affects the productivity and quality of work of the employee, including the quality of food products, is an important indicator of human resource managers when it comes to programs for the improvement of performance of employees. Likewise, in their responsibilities is the management inconsistencies that lead to unsatisfactory performance of employees, eliminate the problems and implement programs that help to increase or maintain employee motivation.

Ensuring the safety of employees in the food industry includes adequate training on the equipment and tools, as well as meet with general security measures. Human resources manager may be responsible for carrying out safety inspections in the workplace and correct any potential hazards, as well as for completing the organizational report on incidents, if an accident occurs in the workplace.

Education and training of employees are factors that directly affect the quality of food products. As previously noted, the food industry of Europe is characterized by a low level of formal education of employees. Conditions of employment in jobs in the manufacturing of food products does not imply a high level of education when it comes to manual jobs, especially for automation and computerization of production facilities. Specific knowledge and skills, employed such as bakers and butchers, are obtained through formal and informal educational programs.

Highly qualified employees, such as dietary technicians, technologists, engineers, engineers for 
the research and development, marketing experts, are more than necessary, especially when we take into account the necessity and obligation of a company engaged in food production to meet the complex criteria related to quality issues, food safety, environmental protection, social responsibility, customer expectations and demand for healthier food products, increasing competitiveness, requires international organizations and regulatory bodies.

Manufacture of food products and beverages is the largest manufacturing sector in the European Union. It employs 4.2 million workers (which is $0.4 \%$ more than in 2011), (FoodDrinkEurope, 2014) and makes $1.8 \%$ of GDP in the EU, and has a relatively large number of businesses and strong demand for labor. The characteristics of the sector, in comparison with other sectors of the economy, are the following: a part-time job, young workers (aged under 30) and a significant percentage of workers with low qualifications (CIAA, 2011).

The food industry is the leading employer in the European Union. According to data from 2013, the European food and drink industry is relatively stable employer for 4.2 million people, but labor productivity is lower than in most manufacturing sectors. The reasons for this are as follows (FoodDrinkEurope, 2014): reduced investment in hiring, machinery and technology, a large number of companies with a small volume of business, $30 \%$ of employees in the food and beverage industry with low-level qualifications (compared to $21 \% \mathrm{a}$ in the overall economy) and a higher number of women in food production in relation to the entire production (43\%: $30 \%)$.

Several studies are conducted on the subject of the need for qualified employees in the food industry of the European Union. However, a good deal of research in recent years has been conducted in the UK at the level of skills in the sector (KPMPC, 2008). In Britain, as in other countries, the food and beverage sector is facing with many problems, thus issues identified in the UK may be useful as a reference point for the food sector across Europe.

Food and beverage industry is one of the industries with the lowest qualified workforce in the UK. About $19 \%$ of employees in this sector have no qualifications, compared to the average of $11 \%$ when it comes to the total number of employees in the UK. Two-thirds of workers in the food industry in England do not have qualifications higher than secondary education. Only $17 \%$ of employees in this sector in England have college or university education, while a third of employees in the manufacturing industry unqualified. In addition, many employers in the sector of food production, in the UK, point out that among the employees there is lack of people with higher education, which has resulted in an increase in operating costs and a slowdown in the introduction of new working practices and innovative products in the sector of the food industry.

In order to meet the requirements for the quality of food products, it is necessary to change practice in the human resource management that is reflected in: training and education of all employees, especially when it comes to standards and customer requirements; recruitment and selection of employees to constant improvement of knowledge, that will have the desire and motivation to improve skills; Communication among employees, between employees and management, but also with customers; evaluation of the performance of employees whose advancement depends on improving the quality of food products; payment system that is stimulating and contributing to the improvement of employee satisfaction and their loyalty to the company they work for. Human resource management requires a strategic role and full involvement in the application of the principles of quality management, in order enable its effective operation and to gaine competitive advantage and offer to market quality food products that meet customer demands for healthier foods, which are in accordance with the standards of international organizations and the recommendations of the World Health organization for the preservation of public health.

\section{METHODOLOGY REASEARCH IN THE ATTITUDES OF EMPLOYEES IN THE FOOD INDUSTRY}

The research that was conducted from December 2013 to May 2014 for the purpose of a doctoral dissertation, in order to highlight the importance and the role of human resources in achieving the quality of food products, included 318 employees in nine companies of the food industry operating in the territory of the Republic Serbia.

For the purpose of this study a structured questionnaire is composed and divided to employee representatives who formed a representative sample. Specific attention was paid 
to include all hierarchical levels of employees in the sample.

Selection of questions and statements is made in such a way that a simple and clear way describes their attitudes and values. Respondents were preacquainted with the variables under examination in order to prevent preferred responses. Respondents answered the questions by circling of answers provided (some questions have allowed several possible answers) or respond to the claim through the offered answers about the degree consent or dissent on a five-point Likert-type scale values. The attitude of every argument was expressed by circling one of the answers. The survey was anonymous.

The questionnaire behind the attitudes of respondents was made out of nine questions (P1 P9), of which the first two are related to the existence of certified quality management system, while in other seven claims the awareness of the respondents in terms of the important factors in achieving quality food products is assessed. Survey questionnaire was aimed to examine the attitudes of employees in the food industry about the significance of factors which influence quality of food products.

Establishing the level of impact of factors on the quality of food products is defined through multivariate approach. In creating the new variables which make the level of impact seven SRPS variables was taken into consideration namely SRPSa (raw materials used for production), SRPSb (technological process), SRPSV (modern equipment and manufacturing plant), SRPSg (quality control methods), SRPSd (education and training of employees), SRPSd (employees satisfaction) and SRPSe (implemented standard or management system). The highest level of correlation was established between the original variables and the division into three groups:

- low level quality impact factor (up to 67.99\%),

- medium level quality impact factor (up to 68 do $81 \%)$

- high level quality impact factor (over $81 \%$ impact).

\section{ATTITUDES OF EMPLOYEES IN THE FOOD INDUSTRY ON THE FACTORS OF FOOD PRODUCTS QUALITY}

During the factor analysis the three groups were observed, constituted on the basis of the degree of determination of the important factors on the quality the food product among the respondents, which represented an important tool in the implementation of the process of grouping. Among the total of 318 surveyed, the first group included 28 subjects who believe that the impact of the aforementioned factors on the quality of food is low, the second group consisted of 108 subjects that characterize this impact as medium, while 182 of surveyed, who recognize the high importance of the influence of technical factors, factors of manpower and standardization in the quality of food products, formed the third group - Figure 1.

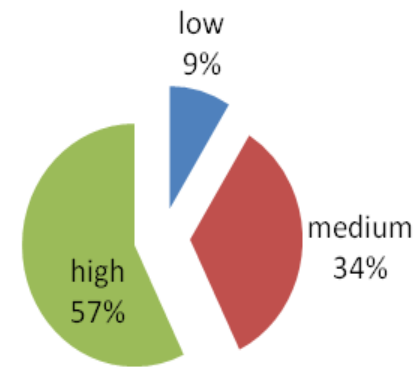

Figure 1: The impact of factors on the quality of food products

Question P1 is trying to determine whether there is a certified quality management system ISO 9001 in the organizations whose employees are in our sample. The results show that $63.2 \%$ of respondents respond affirmatively, $30.8 \%$ of them do not know about the existence of such certified systems within their organizations, while other answers have a total of $6 \%$. It is interesting to what extent employees are not familiar with the efforts of the organization when it comes to the implementation of standards. From the nine companies in which the survey was conducted, only two (BIP and Chipsway) don't have ISO 9001 standard implemented, so if you take into account the fact that these two companies make up to $22.7 \%$ of the entire population gathered around our survey, we could expect that more than $6 \%$ of respondents answered negatively. These results suggest that organizations in many cases do not emphasize enough the importance of keeping their employees informed, which is a direct responsibility of the management of the organization. 
Question P2 refers to the application of other management systems or standards within the organization - Figure 2. Above mentioned observations in relation to keeping all employees informed apply in this case as well. Although HACCP, as legally required standard, is incorporated in all the surveyed companies, only $27.4 \%$ of respondents are aware of this fact. Most respondents, $36.2 \%$, said that their organizations implement an environmental management system, while a similar percentage as in the previous question $(30.5 \%)$ did not know whether their company implemented any of these recommendations. The management systems of health and safety at work with $4.7 \%$ and food safety with $1.7 \%$ proceeds. The final fact is particularly important although Imlek, Sojaprotein and Frikom apply ISO 22000 and make up $48.7 \%$ of the population, only $1.7 \%$ of respondents are aware of this.

Having in mind transparency, seven factors whose impact on the quality of foodstuff is analyzed are grouped as previously stated, in three categories Table 1. The first group includes technological factors, focused exclusively on the production processes (P3 - P6), a second group of factors, which can be characterized as the satisfaction factors or factors of employees, compose simple variables related to education and employee satisfaction (P7 - P8) while a third group of factors present standardization (P9).

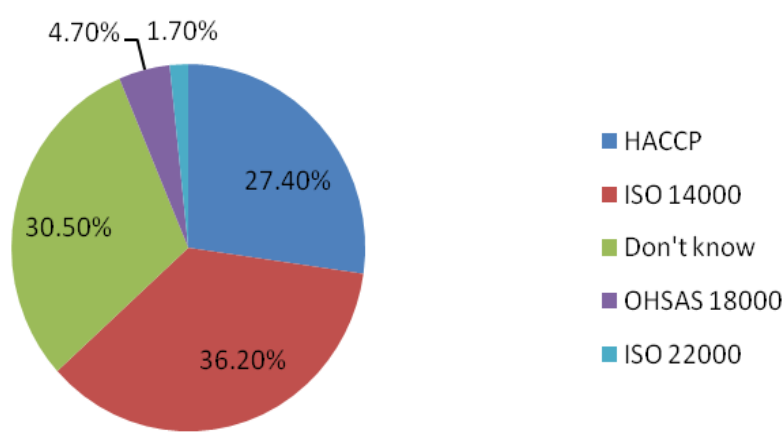

Figure 2: Answers to Question P2: "Does the organization have some other certified management system or standard?"

Table 1: Factors affecting the foodstuff quality

\begin{tabular}{|l|l|c|c|c|}
\hline & \multicolumn{1}{|c|}{ Quality impact factors } & $\begin{array}{c}\text { Average } \\
\text { value } \\
(E)\end{array}$ & $\begin{array}{c}\text { Standard } \\
\text { error } \\
(S E)\end{array}$ & $\begin{array}{c}\text { Standard } \\
\text { deviation } \\
(s)\end{array}$ \\
\hline P3. & The raw materials used for production. & $\mathbf{4 . 4 6}$ & 0.041 & 0.726 \\
\hline P4. & The technological process of production. & $\mathbf{4 . 4 3}$ & 0.039 & 0.688 \\
\hline P5. & Modern equipment and manufacturing plant. & $\mathbf{4 . 1 7}$ & 0.042 & 0.752 \\
\hline P6. & The quality control methods. & $\mathbf{4 . 3 2}$ & 0.042 & 0.748 \\
\hline P7. & Education and training of employees. & $\mathbf{4 . 2 1}$ & 0.045 & 0.809 \\
\hline P8. & Employee satisfaction. & $\mathbf{3 . 8 3}$ & 0.059 & 1.0480 \\
\hline P9. & $\begin{array}{l}\text { Implemented standard or management } \\
\text { system. (eg. ISO 9001: 2008) }\end{array}$ & $\mathbf{3 . 7 2}$ & 0.055 & 0.973 \\
\hline
\end{tabular}

With average score of 4.16 , based on the entire population, we can say that respondents generally recognize these factors as important in achieving foodstuff quality, and that the highest frequency responses are tied to the "I agree" and "I strongly agree" options.

Impact of technological factors on the foodstuff quality is addressed by the allegations P3 - P6. With an average score of 4:35 per the level of sample, we can say that most respondents highly evaluate the impact of this group of factors. Relatively low dispersion parameters indicate a high homogeneity of the responses in which respondents recognize the impact of raw materials used as well as the technological production process as the most important factors in achieving effective foodstuff quality. The methods of quality control are evaluated by employees as of slightly less importance, while the modern equipment and manufacturing plant, although estimated above average by the questionnaire, are in the last place.

Clearly visible, particularly in the first two groups, the apparent downward trend, finds the first confirmation when checking the impact of factors employed in the foodstuff quality. Here we see that, although the average scores 4:02 show that respondents possess positive attitudes, the influence of the employee satisfaction is rated noticeably lower. It is interesting that exactly with this statement the highest value of the standard deviation at the level of the sample was reached, which validates relatively low homogeneity 
answers and explains the fact that in this question the biggest difference in attitudes between the two groups was achieved, even on the scale of 2:11. This tends to cause clearly negative attitudes of members of the first group of respondents who believe that their personal satisfaction has no influence on the effective quality of products. The question concerning the education and training of employed respondents achieved above average score of 4:21 which demonstrates extremely positive attitudes.

The third group of factors, which represents standardization, stands out as a group with the least influence on the achievement of foodstuff quality. This group is characterized, in addition to the relatively low average score of 3.72 , highly negative views of the first as well as the moderate views of other groups of respondents. In other words, even $42.8 \%$ did not have positive views about the impact of standardization on effective quality of products, which could be described as alarming.

To enable a better understanding of the implications of the results, it is necessary to point out an example of Nis Yumis's, whose employees have shown to be extremely conscious when it comes to product quality taking into consideration the very fact that all the respondents from these companies are in the third group. It is obvious that this percentage cannot be regarded as a statistical anomaly, considering the fact that it is based on twenty-five respondents. The only way to explain these results is to conclude that they are a result of the efforts of the management to achieve and maintain an atmosphere of continuous improvement and business development. When it comes to human resources management, this is performed through the implementation of standards: through defining the needed qualifications of employees responsible for the work that affects product quality and ensures their training, keeping records of their education, knowledge and experience, evaluating effectiveness of the taken measures, raising employees awareness about the importance of their participation in the achievement of the quality objectives etc. As the best advocates of these claims are numerous awards, specially the award for the most perspective brand in Serbia in 2013.

\section{CONCLUSION}

From this point of view it becomes evident that the mentioned $42.8 \%$ of respondents whose attitudes in relation to the influence of the standardization and employee satisfaction on the quality cannot be described as positive or clearly defined show unsatisfactory efforts of the organization to define and act upon adequate quality policy. Based on what has been said it is clear that with increasing awareness of the quality grows the perceived level of product quality, while on the other hand it has been apparent that awareness of quality is directly dependent on the efforts of management of the organization. Conclusions presented in the individual claims of this study indicate that it is necessary: to strive towards more effective and efficient implementation of ISO 9001: 2008 standards, as well as other management systems (particularly shown in questions P1, P2 and P9); to inform the employees about the organization's aspirations in greater scale (questions P1 and P2); to encourage employees to innovate and develop employees awareness about the importance of their participation in the achievement of quality objectives (issue P8), as well as to expand the awareness of quality (e.g. company Yumis). It should be added that all the above mentioned activities fall under the direct jurisdiction of the top management of the organization.

\section{REFERENCES}

Anthony, M. (2012). Flavor Trends for 2012: What flavors will entice consumers in 2012? Think ethnic fusions, authentic' spice blends and exotic fruits. Retrieved 07.04.2015, from Food Processing http://www.foodprocessing.com/articles/2012/flavor -trends-for-new-year/?start $=0$

BLS. (2008). Injuries, Illnesses, and Fatalities in Food Manufacturing. Retrieved 24.12.2014 http://www.bls.gov/opub/mlr/cwc/injuries-illnessesand-fatalities-in-food-manufacturing-2008.pdf

BLS. (2015) Retrieved 18.03.2015, from http://www.bls.gov/home.htm

CIAA. (2011). Data \& trends of the European Food and Drink Industry 2010. Retrieved 14.03.2015 http://www.fooddrinkeurope.eu/uploads/pressreleases_documents/Data_trends_of the European Food_and_Drink_Industry_2010.pdf

Ergonomic Guidelines for Manual Material Handling. (2007). Retrieved 01.04.2015, from Cal/OSHA Consultation Service, Research and Education Unit, Division of Occupational Safety and Health, California Department of Industrial Relations https://www.dir.ca.gov/dosh/dosh_publications/mmh .pdf

FAO. (2012). The State of Food Insecurity in the World. Retrieved 01.04.2015, from FAO http://www.fao.org/docrep/016/i3027e/i3027e.pdf

Filipović, J., \& Đurić, M. (2009). Osnove kvaliteta. Belgrade, Serbia: FON. 
FoodDrinkEurope. (2014). Data \& Trends of the European Food and Drink Industry 2013-2014. Retrieved 20.12.2014 http://www.fooddrinkeurope.eu/uploads/publications _documents/Data_Trends_of the_European_Food and_Drink_Industry_2013-2014.pdf

Hartmann, M. (2011). Corporate social responsibility in the food sector.European Review of Agricultural Economics, 38(3), 297-324.

Hruškar, M., Medić, H., Vahčić, N., \& Bauman, I. (2010). Upravljanje kvalitetom hrane - Quality management systems (ISO 9001). Zagreb, Croatia: University of Zagreb, Faculty of Food Technology and Biotechnology.

Infor. (2012). How food \& beverage companies gain competitive advantage: The importance of implementing a least-cost formulation strategy. Retrieved 21.01.2015 http://www.infor.com/content/whitepapers/howfood andbevgainadvantage.pdf/

Kennedy, G., Nantel, G., \& Shetty, P. (2004). Globalization of food systems in developing countries: a synthesis of country case studies. In K. Tontisirin (Ed.), Globalization of food systems in developing countries: impact on food security and nutrition (pp. 1-24). Rome, Italy: FAO.

KPMPC. (2008). Study of Food Products and Beverages Industry: Research report on skill needs. Retrieved
19.03.2015, from Methodological Centre for Vocational Education and Training http://www.kpmpc.lt/Skelbimai/SEK_EN/ENMaist.\%20sekt08.07.30.pdf

Leung, X. Y., Hertzman, J., \& Erdem, M. (2011). Food Companies' Corporate Social Responsibility Regarding Food Safety: A Content Analysis of Restaurant Websites.

http://scholarworks.umass.edu/cgi/viewcontent.cgi?a rticle $=1146 \&$ context $=$ gradconf_hospitality

Luning, P. A., Marcelis, W. J., \& Jongen, W. M. F. (2002). Food quality management: a technomanagerial approach: Wageningen Pers.

Maloni, M., \& Brown, M. (2006). Corporate Social Responsibility in the Supply Chain: An Application in the Food Industry. Journal of business ethics, $68(1), 35-52$.

Powell, T. C. (1995). Total quality management as competitive advantage: a review and empirical study. Strategic management journal, 16(1), 15-37.

SIEPA. (2015) Retrieved 11.02.2015, from http://siepa.gov.rs/sr/index/standardi/organicsertifikat.html

WHO. (2013). Obesity and overweight. Retrieved 11.02.2015 from: http://www.who.int/mediacentre/factsheets/fs311/en/ 